\title{
Correction to: A Compendium of Solid State Theory
}

\section{Correction to:}

\section{A. Bányai, A Compendium of Solid State Theory,}

https://doi.org/10.1007/978-3-030-37359-7

The author's affiliation that is displayed in the book and on the website is not actually the author's affiliation, but rather his location (Oberursel being a city in Germany, not an institution).

"Oberursel, Germany"

Therefore, this has now been updated as:

Institut für Theoretische Physik, Goethe Universität, Frankfurt am Main, Germany 